\title{
A Literature Review of Learning from Failure and Prospects for Future Research
}

\author{
Huimin Li a, Qinpu Zhang ${ }^{b}$ \\ School of Management, Harbin Institute of Technology, Harbin 150000, China \\ a396994516@qq.com, bzzqp2000@126.com
}

\begin{abstract}
In the constantly changing commercial field, learning from failure can reduce risks of organization failure and improve the organizational innovation performance. By collating domestic and overseas scholars' research achievements about learning from failure from different angles, based on the perspective of effects about learning from failure, this paper analyzes the influence of learning from failure on different angles combining with the target of improving the innovation performance of modern enterprises, and proposes the model framework about the effects of learning from failure. Finally, on the basis of commenting the existing researches, it gives the prospect of the future research direction.
\end{abstract}

Keywords: Learning from failure; Effects; Innovation performance.

\section{Introduction}

In the constantly changing market environment, enterprises are faced with far higher possibility of failure than that of success. Therefore, it is the key to stepping over the failure and making a success in the future for enterprises to acquire valuable information from failure and to study the failure experience in a targeted way [1]. However, it is not easy to learn from failure for either the individual or an organization. Owing to the "success prejudice" prevalent in commercial field, people are unwilling to face failure and ashamed of talking about failure. Most previous researches do not attach importance to the value of learning from failure; they just emphasize learning from the past experience of success, but ignore the important value of failure experience [2].

Therefore, this paper plans to collate the existing literature about learning from failure from the aspects of connotation, influence factors, and effects of learning from failure. Moreover, based on the perspective of effects about learning from failure, by combining with the target of modern enterprises to improve innovation performance, we propose the model framework about the effects of learning from failure on organizational innovation performance. Finally, a prospect is given to the future research direction of this field.

\section{A brief review of researches on learning from failure}

Researches on learning from failure can date back to the study of Simon (1957) about management decision-making theory [3]. According to the study, the experience of failure is more meaningful for some decision-making processes, so this research becomes the prototype for the research field of learning from failure. Later many scholars have studied the organizational learning mechanism in decision-making process. Fredland \& Morris (1976) pointed out that the experience of failure was the origin of special contents in organizational learning [4]. This can be treated as the formal starting point of researches on learning from failure. What is more important in organizational learning researches, the experience of success or the experience of failure? Scholars have given the answer from different angles. Levitt \& March (1988) and Morris \& Moore (2000) considered that compared with the experience of success, the experience of failure could better stimulate decision makers to seek a more effective problem solution and help decision makers optimize the decision-making process[5][6]. Scholars like Fredland, Morris, et al. have opened the door of researches on learning from failure, making numerous scholars explore problems in the field of learning from failure. 
In the research field of learning from failure, scholars' concept definition about "failure" is still vague. Concepts like "failure", "error" and "mistake" are often mixed in various literature. Therefore, it is necessary to collate and accurately give the definition of "failure". In earlier studies, Bruno, Mcquarrie, Torgrimson (1992) defined failure as the situation where a certain business was stopped under compulsion due to various reasons. Tucker, Edmondson and Spear (2002) defined failure as the situation where the organizational performance could not reach the established target due to errors or problems produced in the operation process from the angle of organizational behavior[7]. Later Shepherd (2014) considered that failure was an action that did not reach the target; however, failure could bring about a good effect if the opportunities could be grasped [8]. After summarizing the above scholars' research viewpoints, we consider that learning from failure refers to the process in which the organization reflects on and studies the internal and external failure experience, and adjusts its behaviors to reduce the probability of failure and to improve the organizational performance in the future.

By collating various literature, we discover that in researches about learning from failure, most scholars mainly pay attention to three aspects. Firstly, it is the content origin of learning from failure. For instance, Tucker and Edmondson (2003) believed that the contents of learning from failure came from the experience of failure within the organization [9]. However, Baum \& Dahlin (2007) considered that the contents of learning from failure originated from the experience outside the organization [10]. Secondly, it comes to influence factors of learning from failure. "Small failure theory" and "big failure theory" are two mainstream viewpoints. Scholars advocating small failure theory consider that failure is beneficial to organizational learning, while scholars supporting big failure theory investigate the relation between failure severity and learning from the angle of knowledge management [11]. In the third part, this paper summarizes relevant research statuses about influence factors of learning from failure. Finally, it comes to the significance and effects of learning from failure (also known as result of learning from failure). Under this perspective, scholars think that the greatest significance of learning from failure is the improvement of organizational performance and increase of efficiency [12]. For most enterprises of industry and commerce, the ultimate purpose of exploring learning from failure is to optimize decision-making process of the organization, to improve business efficiency, and to enhance organizational performance by learning the experience of failure. Therefore, it has an important influence on organizational performance.

\section{Influence factors of learning from failure}

The existing researches mainly analyze influence factors of learning from failure from internal factors and external environment. Internal factors mainly include self-leadership and emotion adjustment [13], past experience of success [14], learning motivation [15]; external environment studies mainly focus on organizational system and organizational environment. By combining with domestic and overseas researches, this paper collates influence factors of learning from failure from three levels covering individual, team and organization.

\subsection{Influence factors at individual level}

Influence factors at individual level can be summarized into internal motivation of the individual [16] and past experience of failure [17]. Firstly, internal motivation means that the individual has an internal need of establishing a set of new methods after failure, and such need will help them learn the failure more effectively. Secondly, the individual' s past experience of failure will influence the next learning behavior from failure [18], and students with entrepreneurial experience have a deeper understanding about failure [19]. As for reflections of the influence of such past experience on learning from failure at micro psychological level, self-adjustment and self-leadership of the individual can help people recover from failure quickly; moreover, the psychological sense of security at individual level will influence learning from failure in the entire organization [20]. 


\subsection{Influence factors at team level}

Based on influence factors at individual level, learning from failure is also reflected as the dynamic learning process between team members. Dean, Yu \& Hui (2004) pointed out in their studies that sharing mental mode, cooperation culture and problem solving orientation were beneficial to learning from failure. On the other hand, inhibiting factors of the influence on learning from failure at team level mainly include the inhibiting effect of interpersonal relation disturbance on learning from failure, the inhibiting effect of team error severity on learning from failure [21], the inhibiting effect of team CEO unwilling to assume responsibilities on learning from failure, etc.

\subsection{Influence factors at organization level}

Farson \& Keyes (2002) pointed out the influence of organization tolerance for failure on employees' psychological mood and the influence on employees' learning process from failure from organization level. Cannon \& Edmondson (2005) discussed the influences on learning from failure by directing at various aspects covering work design in the organization, information gathering, social psychological factors, management, rewards and punishment mechanism, organization structure and system process from technology level and social environment. In addition, the distribution system of punishing failure and whether there is a supportive work environment [22] will also generate an important influence on employees' learning from failure.

By collating the existing researches, the following figure is gained (Fig.1).

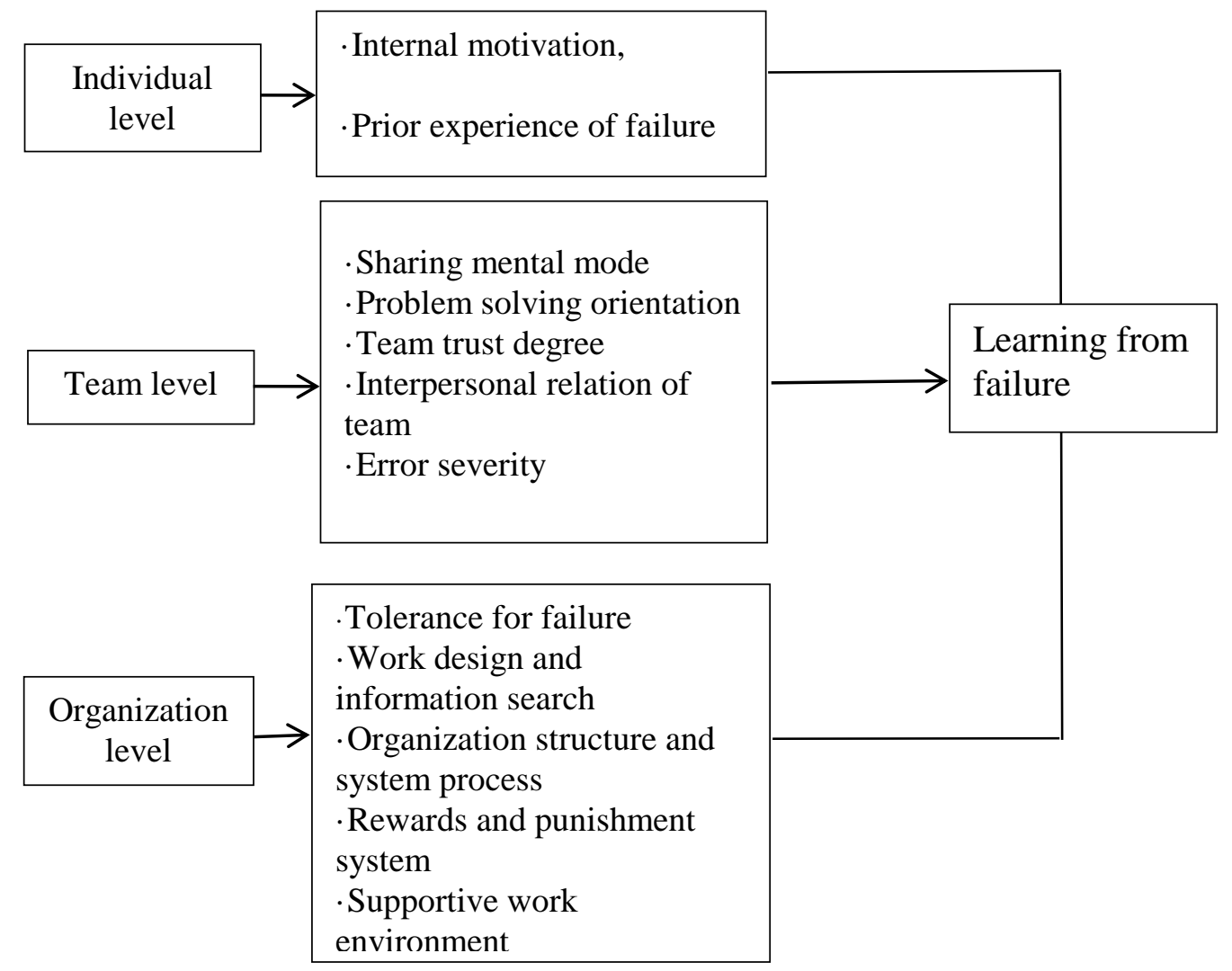

Fig. 1 Influence factors of learning from failure

\section{Effects of learning from failure}

When market competition becomes increasingly fierce, more and more enterprises begin to notice the positive effect of organizational learning on business efficiency increase. As a brand-new research perspective of organizational learning field, learning from failure has gained increasing attention from scholars. At present, most scholars have proven that the experience of failure is more valuable than the experience of success in adjustment of enterprise behaviors and improvement of efficiency. What specific effects does learning from failure have? By collating literature, we mainly summarize the 
action mechanism of organizational learning from two aspects covering positive effect and negative effect.

\subsection{The positive effect}

The effect of learning from failure on individual is mainly reflected in adjustment of individual knowledge reserve, accumulation of experience, enhancement of future success probability, and improvement of self-behaviors. Relevant qualitative and quantitative researches are not perfect. Most scholars explore learning from failure at team and organization levels. The effect of learning from failure at team level is mainly reflected in the improvement of decision-making quality in the team [23], increase of team members' future performance [24], etc. The effect of learning from failure at organization level is mainly reflected in the following aspects: 1) improvement of organizational innovation performance. Argote, Beckman and Epple (1990) put forward that learning from failure could increase service quality, adaptation and innovation of the organization [12]. Carmeli and Schaubroeck (2008) studied the fire hazard in a chemical firm of Israel, and pointed out that learning from failure could improve crisis response efficiency of the organization and increase organizational performance [25]. 2) Increase of success probability in the future. Cope (2011) discovered through the study that learning behavior after entrepreneurial failure would help to increase the probability of entrepreneurial success in the future [26]. Meschi and Métais (2015) studied the acquisition failure event of a certain enterprise, and found that learning from the experience of failure would improve the future acquisition performance [27]. 3) Reduction of the failure probability. Haunschild and Sullivan (2002) considered that learning from failure could reduce accident rate in the organization [28]. Baum (1998) pointed out that learning from failure would reduce failure risk of the organization.

\subsection{The negative effect}

In the research field of learning from failure, not all scholars consider that the experience of failure is more useful than the experience of success. Liisa Valikangas (2009) considered that the trauma caused by innovation failure might result in serious disappointment among employees and hinder the follow-up innovative behaviors [29]. Shepherd \& Cardon (2009) considered that negative emotion produced by the individual in failure would generate a negative effect on the future attempt [30]. Madsen and Desai (2010) pointed out that if there was a lack of learning experience from failure and learning from failure was conducted blindly, wrong knowledge would be learned and failure might be caused again [31].

By summarizing the above research results, we propose a model framework about the effects of learning from failure, as shown in the following figure (Fig.2). 


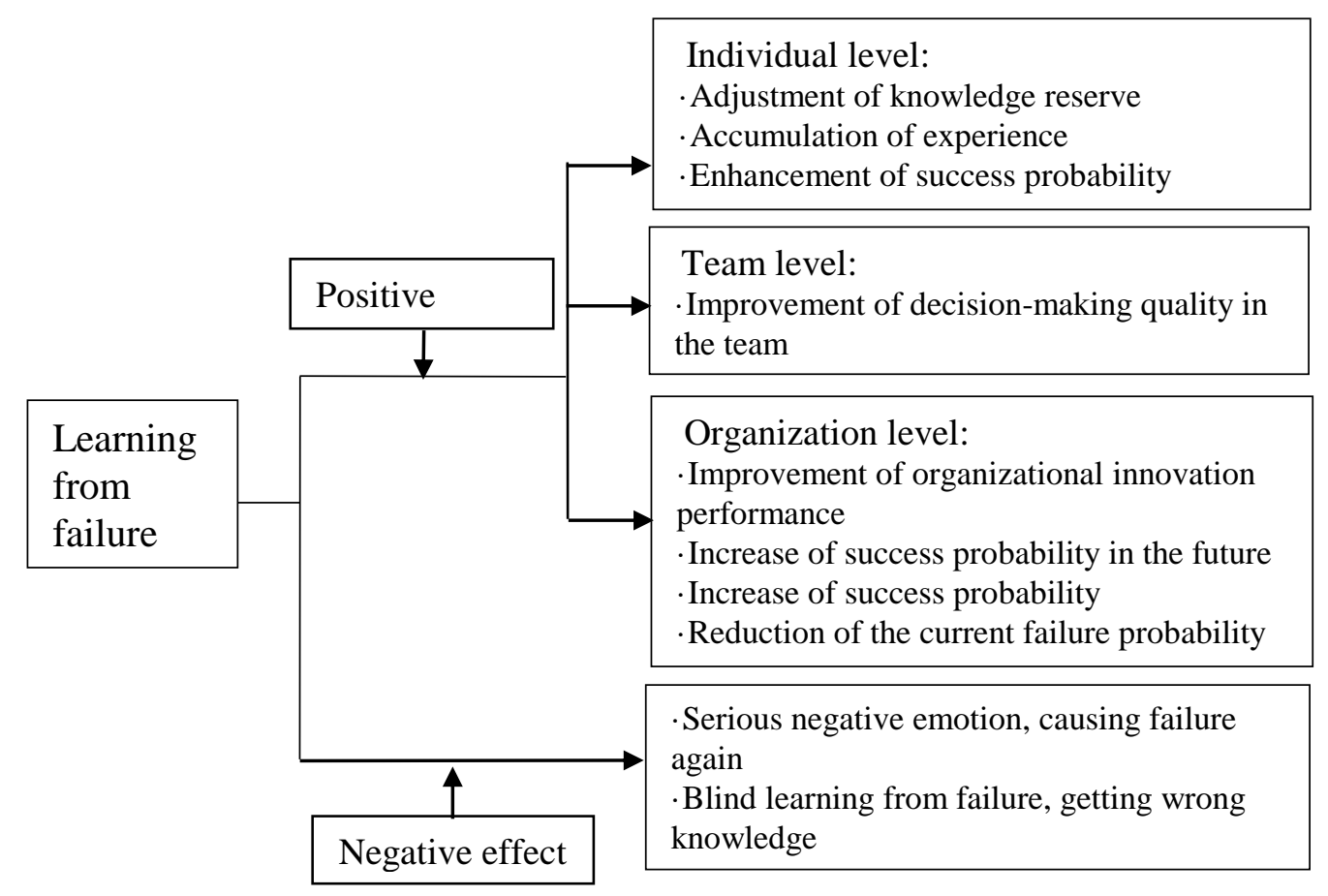

Fig. 2 Model of the effects of learning from failure

\section{Summary and future prospect}

Learning from failure is a hot issue in the research field of organizational learning. Learning from failure experience plays an important role in reducing accident rate, improving innovation performance and increasing future success probability for the organization.

At present, researches about learning from failure in the academic circles mainly focus on concept and connotation, influence factors, significance and action mechanism of learning from failure. According to the evolution process of organizational learning researches, study on the action mechanism of learning from failure has immeasurable values in revealing the importance of learning from failure experience and clarifying the objective of learning from failure. Therefore, the research from the perspective of action mechanism will attract attention from more scholars in the future. Researches in this field have already gained many valuable achievements at present, but there is still a space for further exploration.

In the future, the research based on the action mechanism of learning from failure can be carried out from the following aspects.

Firstly, the output effect and formation mechanism of learning from failure should be excavated deeply, so as to make the theory about learning from failure better serve enterprise management practice.

Secondly, an in-depth discussion should be made on the results of learning from failure; qualitative or quantitative researches must be conducted for the positive effect and negative effect of learning from failure, so as to improve the value of learning from failure.

Finally, a quantitative study should be made for the influence of learning from failure on organizational innovation performance, and exploration must be conducted for whether such influence has a threshold value. In this way, enterprises will be able to carry out learning from failure in a more effective way and improve the efficiency of learning from failure.

\section{References}

[1] D. Ucbasaran. The nature of entrepreneurial experience, business failure and comparative optimism [J]. Journal of Business Venturing, 2010, 25(6):541-555. 
[2] Hsu Dan K, Wiklund, R. D. Cotton. Success, failure and entrepreneurial reentry: An experimental assessment of the veracity of self-efficacy and prospect theory $[\mathrm{J}]$. Entrepreneurship Theory and Practice, 2015.

[3] H. H. Hu, C. M. Wong .Research status and future prospects of learning from failure in foreign countries [J]. Foreign economy and management, 2011(11): 39-47.

[4] E. J. Fredland, C. E. Morris. A cross-section analysis of small business failure [J]. American Journal of small Business, 1976, 32(1):7-18.

[5] B. Levitt, J. G. March. Organizational learning [J]. Annual Review of Sociology, 1988, 14(2): 319-340.

[6] M. W. Morris, P. C. Moore. The lessons we (don't) learn: Counterfactual thinking and organizational accountability after a close call [J]. Administrative Science Quarterly, 2000, 45(4): 735-765.

[7] A. L. Tucker, A. C. Edmondson, S. Spear. When problem solving prevents organizational learning [J]. Organizational Change Manage, 2002, 15(2):122-136.

[8] D. A. Shepherd. How does project termination impact project team members? Rapid termination, 'creeping death', and learning from failure [J]. Journal of Management Studies, 2014, 51(4): 513-546.

[9] A. L. Tucker, A. C. Edmondson. Why hospital don't learn from failures: Organizational and psychological dynamics that inhibit change [J]. California Management Review, 2003, 45(2): $55-72$.

[10] J. A. Baum, K. B. Dahlin. Aspiration performance and railroads' patterns of learning from train wrecks and crashes [J]. Organizational Science, 2007, 18(3):368-385.

[11]M. P. Madsen, Vinnit Desai. Failing to learning? The effects of failure and success on organizational learning in the global orbital launch vehicle industry. Academy of Management Journal, 2010, Vol.53. No.3: 451-476.

[12]L. Argote, S. L. Beckman, D. Epple. The persistence and transfer of learning in industrial settings [J]. Management Science, 1990, 36(2): 140-154.

[13] A. D. Boss, H. P. S. Jr. Everyone fails! Using emotion regulation and self-leadership for recovery [J]. Journal of Managerial Psychology, 2008, 23(2): 135-150.

[14] S. Ellis, I. David. After-event reviews: Drawing lessons from successful and failed experience [J]. Journal of Applied Psychology, 2005, 90(5): 857-871.

[15]B. Zhao. Learning from errors: The role of context, emotion, and personality [J]. Journal of Organizational Behavior, 2011, 32(3): 435-463.

[16] Y. Yamakawa, M. W. Peng, D. L. Deeds. Rising from the ashes: Cognitive determinants of venture growth after entrepreneurial failure [J]. Entrepreneurship Theory and Practice, 2013, 39(2): 209-236.

[17]K. Muehlfeld, P. R. Sahib, A. V. Witteloostuijn. A contextual theory of organizational learning from failures and successes: A study of acquisition in the global newspaper industry, 1998-2008[J]. Strategic Management Journal, 2012, 33(8): 938-964.

[18] J. Amankwah-Amoah. Learning from the failures of others: The effects of post-exit knowledge spillovers on recipient firms [J]. Journal of Workplace Learning, 2011, 23(6): 358-375.

[19]A. R. Bolinger, K. D. Brown. Entrepreneurial failure as a threshold concept: The effects of student experiences [J]. Journal of Management Education, 2015, 39(4): 452-475. 
[20]A. Carmeli, J. H. Gittell. High quality relationship, psychological safety and learning from failures in work organizations [J]. Journal of Organizational Behavior, 2009, 30(6): 709-729.

[21] M. D. Cannon, A. C. Edmondson. Confronting failure: Antecedents and consequences of shared beliefs about failure in organizational work groups [J]. Journal of Organizational Behavior, 2001, 22(2):161-177.

[22] S. Sitkin. Learning through failure: The strategy of small losses [A]. In B. Staw, L. Cummings (Eds.). Research in organizational behavior[C]. Greenwich, CT: JAI Press, 1992.

[23] A. Carmeli, A. Tishler and A. C. Edmondson. CEO relational leadership and strategic decision quality in top management teams: The role of team trust and learning from failure [J]. Strategic Organization, 2012, 10(1): 31-54.

[24] R. Hirak. Linking leader inclusiveness to work unit performance: The important of psychological safety and learning from failures [J]. The Leadership Quarterly, 2012, 23(1): 107-117.

[25] Abraham Carmeli, John Schaubroeck. Organizational crisis-preparedness: the importance of learning from failures [J]. Long Range Planning, 2008, 41: 177-196.

[26] Cope, Entrepreneurial learning from failure: An interpretative phenomenological analysis [J]. Journal of Business Venturing, 2011, 26(6): 604-623.

[27]P. Meschi, E. Métais. Too big to learn: The effects of major acquisition failures on subsequent acquisition divestment [J]. British Journal of Management, 2015, 26(3): 408-423.

[28]P. R. Haunschild, B. N. Sullivan. Learning from complexity: Effects of prior accidents and incidents on airlines' learning [J]. Administrative Science Quarterly, 2002, 47: 609-643.

[29]Liisa Valikangas, Martin Hoegl, Michael Gibbert. Why learning from failure isn't easy (and what to do about it): Innovation trauma at Sun Microsystems. European Management Journal, 2009, 27: $225-233$.

[30]D. A. Shepherd, M. S. Cardon. Negative Emotional Reactions to Project Failure and the Self-Compassion to Learn from the Experience. Journal of Management Studies, 2009, 46(6): 923-949.

[31]P. M. Madsen, V. Desai. Failing to learn? The effects of failure and success on organizational learning in the global orbital launch vehicle industry [J]. Academy of Management Journal, 2010, 53(3): 451-476. 